\title{
Review
}

\section{Neuronal protection and destruction by NO}

\author{
Stuart A Lipton*,1 \\ ${ }^{1}$ The CNS Research Institute, Brigham and Women's Hospital, and Program in \\ Neuroscience, Harvard Medical School, Boston, MA 02115 USA \\ * corresponding author: Stuart A Lipton, Prof. and Director, Center for \\ Neuroscience and Aging Research, The Burnham Institute, 10901 North \\ Torrey Pines Road, La Jolla, CA 92037, USA. \\ tel: 858713 6260; fax: 858713 6262; \\ e-mail: Slipton@burnham-inst.org
}

Received 6.4.99; accepted 15.7.99

Edited by G. Melino

\begin{abstract}
Nitric oxide (NO)-related species include different redox states of the NO group, which have recently been reported to exist endogenously in biological tissues including the brain. The importance of these different NO-related species is that their distinct chemical reactivities can influence the life and death of neurons in response to various insults. In the case of $\mathrm{NO}^{+}$equivalents (having one less electron than NO*), the mechanism of reaction often involves Snitrosylation or transfer of the NO group to the sulfhydryl of a cysteine residue (or more properly to a thiolate anion) to form an RS-NO; further oxidation of critical thiols can possibly then form disulfide bonds from neighboring cysteine residues. We have mounted both physiological and chemical evidence that $\mathrm{N}$-methyl-D-aspartate receptor (NMDAR) activity and caspase enzyme activity can be decreased by S-nitrosylation, as can other signaling molecules involved in neuronal apoptotic pathways, to afford neuroprotection. Over the past 5 years, beginning with our report on the NMDAR, evidence has accumulated that S-nitrosylation can regulate the biological activity of a great variety of proteins, in some ways akin to phosphorylation. Thus, this chemical reaction is gaining acceptance as a newly-recognized molecular switch to control protein function via reactive thiol groups, such as those encountered on the NMDAR and in the active site of caspases. One method of producing S-nitrosylation of the NMDAR and caspases is the administration of nitroglycerin, and nitroglycerin can be neuroprotective in acute focal ischemia/reperfusion models via mechanisms other than increasing cerebral blood flow. In contrast, NO• itself does not appear to react with thiol under physiological conditions. In fact, the favored reaction of $\mathrm{NO}^{-}$is with $\mathrm{O}_{2}{ }^{--}$(superoxide anion) to form $\mathrm{ONOO}^{-}$(peroxynitrite), which can lead to neurotoxicity. A third NO-related species with one added electron compared to $\mathrm{NO}^{-}$is nitroxyl anion
\end{abstract}

$\left(\mathrm{NO}^{-}\right)$. $\mathrm{NO}^{-}-$unlike $\mathrm{NO}^{-}$but reminiscent of $\mathrm{NO}^{+}$ transfer-reacts with critical thiol groups of the NMDA receptor to curtail excessive $\mathrm{Ca}^{2+}$ influx and thus provide neuroprotection from excitotoxic insults.

Keywords: nitric oxide; NMDA receptor; caspases; peroxynitrite; S-nitrosylation; NO-related species

Abbreviations: NMDAR, N-methyl-D-aspartate receptor;NMDARSNO, S-nitrosylated NMDAR; SNOC, S-nitrosocysteine

\section{Redox reagents and NO-related species can react with cysteine sulfhydryls to regulate protein function}

Redox modulation by covalent modification of sulfhydryl (thiol) groups on protein cysteine residues can regulate protein function. If they possess a sufficient redox potential, oxidizing agents can react to form adducts on single sulfhydryl groups or, if two free sulfhydryl groups are vicinal (in close proximity), disulfide bonds may possibly be formed. Reducing agents can regenerate free sulfhydryl $(-\mathrm{SH})$ groups by donating electron(s). One example of a protein possessing the potential for physiological regulation by redox agents is the NMDA receptor; another is the family of caspase enzymes which have a critical cysteine residue in their active site. The redox modulatory sites of the NMDA receptor consist of critical cysteine residues which, when chemically reduced, increase the magnitude of NMDA-evoked responses. In contrast, after oxidation, NMDA-evoked responses are decreased in size. Considering endogenous redox agents, in addition to the usual suspects including glutathione, lipoic acid, and reactive oxygen species, nitric oxide-related species have recently come to the fore. This has occurred largely because of the rediscovery and application to biological systems of work from the early part of this century showing the organic synthesis of nitrosothiols (RS-NO). ${ }^{1}$ NO-related species include nitric oxide $\left(\mathrm{NO}^{\circ}\right)$ and nitrosonium ion equivalents $\left(\mathrm{NO}^{+}\right)$, with one less electron than $\mathrm{NO}^{\circ}$, as well as nitroxyl anion $\left(\mathrm{NO}^{-}\right)$with one additional electron compared to $\mathrm{NO}^{\bullet} .^{1}$ Recent evidence suggests these redoxrelated forms or their functional equivalents are important pharmacologically and physiologically, participating in distinctive chemical reactions. $\mathrm{NO}^{+}$can be transferred (not as free $\mathrm{NO}^{+}$but as an intermediate that functionally donates $\mathrm{NO}^{+}$) from either endogenous or exogenous donors to thiol. This reaction is termed S-nitrosylation and forms nitrosothiols, for example, we believe on the NMDA receptor (NMDAR$\mathrm{SNO}$ ). The reaction of the NO group with NMDAR thiol decreases NMDA-evoked responses similar to an oxidizing agent. A consensus motif of amino acids comprised of nucleophilic residues surrounding a critical cysteine, which 
increase the cysteine sulfhydryl's susceptibility to S-nitrosylation by $\mathrm{NO}^{+}$donors, has been proposed; NMDAR subunits contain multiple typical consensus motifs for S-nitrosylation, ${ }^{2}$ and site-directed mutagenesis work on recombinant NMDAR subunits indicate that these cysteine residues indeed react with $\mathrm{NO}^{+}$donors, but only if the cysteine residues are in the reduced (free sulfhydryl) state. $\mathrm{NO}^{-}$in its singlet or highenergy state can also react with thiol, for example, on the NMDAR. ${ }^{3}$ However, $\mathrm{NO}^{\bullet}$ in general will not react with thiol, and instead can lead to a neurodestructive pathway via reaction with $\mathrm{O}_{2} \cdot-$ to form $\mathrm{ONOO}^{-}$(peroxynitrite). ${ }^{4}$ This review summarizes these processes and the evidence for and against their existence in the nervous system.

\section{Reactive nitrogen intermediates (RNI) as physiological messenger or pathological mediator of apoptosis}

$\mathrm{RNI}$ are generated by the progressive oxidation of the terminal guanidine residue of L-arginine by nitric oxide synthase (NOS) to produce the NO group, although the exact NO-related species generated is still contentious. Further oxidation leads ultimately to nitrate, with $\mathrm{RNI}$ including $\mathrm{NO}_{2}, \mathrm{~N}_{2} \mathrm{O}_{3}, \mathrm{~N}_{2} \mathrm{O}_{4}$, and physiological $\mathrm{NO}$ adducts such as S-nitrosothiols and peroxynitrite $\left(\mathrm{ONOO}^{-}\right)$. Three different forms of NOS have been identified, two of which are constitutive and occur in neurons nNOS (or NOS1) and possibly eNOS (or NOS3; eNOS was originally cloned from endothelial cells). Inducible NOS (iNOS or NO2) occurs in the nervous system in astrocytes and microglia. The constitutive forms of NOS are activated by $\mathrm{Ca}^{2+}$ via calmodulin.

The NO group has a dual role as physiological messenger and as a contributor to lethal processes. Classically, 'NO' mediates endothelium-dependent relaxation, takes part in neurotransmission, and is a key player in the cellular immune response. ${ }^{5}$ Multiple reactions occur between oxygen, superoxide, and transition metals with the following products: $\mathrm{N}_{2} \mathrm{O}_{3}$ [equivalent to $\left(\mathrm{NO}_{2}{ }^{-}\right)\left(\mathrm{NO}^{+}\right)$], peroxynitrite $\left(\mathrm{OONO}^{-}\right)$, and metal-NO adducts, respectively. These reactions determine the biological activity of the NO group in its various redox-related forms. Other reactions involving the transfer of $\mathrm{NO}^{+}$equivalents (with one less electron than $\mathrm{NO}^{\bullet}$ ) result in nitrosative reactions at nucleophilic centers with critical cysteine sulfhydryls, producing S-nitrosothiol formation. This reaction, termed S-nitrosylation, occurs preferentially at specific consensus motifs of amino acid residues centered around a critical cysteine sulfhydryl which reacts with the NO group, and serves to regulate protein function akin to phosphorylation of critical serine, threonine, or tyrosine residues. ${ }^{2,4}$ Accordingly, thiol- and transition metal-containing proteins serve as major target sites for NO-related species. ${ }^{6} \mathrm{NO}-$ target interaction achieves both cGMP-dependent and cGMP-independent transducing mechanisms. Cyclic GMPindependent $\mathrm{NO}$-induced responses account for the antimicrobial, the cytostatic, and in many cases the cytotoxic capacity of NO-related species. Excess production of $\mathrm{NO}^{-}$has been shown to underlie, at least in part, glutamate-induced neuronal toxicity in cultures of cortical and striatal neurons. ${ }^{7}$ Finally, radicals generated by the interaction of $\mathrm{NO}^{\bullet}$ with oxygen species can induce DNA damage. $^{8}$ Our own studies have recently focused on the cytotoxicity of nitric oxide in conjunction with reactive oxygen species in cerebrocortical neurons.

\section{NO induced neuronal cell death: contribution to apoptosis}

Excessive activation of excitatory amino acid receptors and the subsequent generation of free radical species has been implicated as a mechanism for neurotoxicity in both acute and chronic neurological diseases, ranging from stroke and head trauma to Alzheimer's disease and amyotrophic lateral sclerosis to Huntington's disease and AIDS dementia. ${ }^{9-13}$ This form of neuronal cell death has been termed 'excitotoxicity' by John Olney. The underlying process responsible for neuronal cell death after overactivation of glutamate receptor subtypes - of which the NMDAR plays a prominent role because of its high permeability to $\mathrm{Ca}^{2+}$ - have only recently begun to be clarified. In a wide variety of neurologic disorders, such as stroke, head trauma, AIDS dementia, and glaucoma, excitotoxicity may be related to excessive glutamate release and/or lack of clearance, which results in excessive stimulation of NMDARs. ${ }^{13}$ This can result in either an acute or chronic process, possibly dependent on the level of NMDA receptor stimulation and NO\%proxynitrite generation. ${ }^{14}$ Other excitatory amino acid receptor subtypes also contribute to these processes, but in many cases the NMDA receptor has a prominent role.

The interaction of glutamate with excitatory amino acids receptors initiates a cascade of events involving excessive $\mathrm{Ca}^{2+}$ entry and activation of several enzymes, including phospholipases, proteases, and NOS. ${ }^{9-13}$ Phospholipase $A_{2}$ activation leads to the generation of arachidonic acid and other metabolites as well as to the formation of oxygen free radicals. This can lead to a combination of oxidative and nitrosative stress, culminating in peroxynitrite formation and neuronal cell death. ${ }^{4,15}$ The cell death pathway can be either necrotic or apoptotic, depending on the intensity of the insult. ${ }^{14}$ To show this, we investigated whether apoptosis or necrosis can be induced in cerebrocortical neurons in culture by overstimulation of glutamate receptors, with consequent influx of excessive $\mathrm{Ca}^{2+}$, and downstream production of $\mathrm{NO}^{\bullet}$ and $\mathrm{O}_{2}{ }^{\bullet-}$. We used high and low concentrations of glutamate agonists (such as NMDA), NO-donors [such as 3-morpholinosydnonimide $(\mathrm{SIN}-1)$ and S-nitrosocysteine (SNOC)], or peroxynitrite $\left(\mathrm{OONO}^{-}\right)$. We found that exposure of cortical cultures to relatively short durations or low concentrations of NMDA, SNOC, SIN-1, or peroxynitrite induced delayed neuronal cell death characterized by apoptotic features. In contrast, intense exposure to high concentrations of NMDA or peroxynitrite induced relatively rapid necrotic cell death in neurons. ${ }^{14}$ Superoxide dismutase (SOD) and catalase attenuated neuronal cell death, most likely by reducing the formation of peroxynitrite since they were only effective if peroxynitrite had not yet formed. These findings suggest that the intensity of the original insult may determine the ensuing pathway to either necrotic or apoptotic neuronal cell death. The nature of the original insult as well as the 
decision to enter the necrotic versus the apoptotic pathway might have therapeutic implications in terms of the possible effectiveness of SOD/catalase or NMDAR-antagonists, as well as the necessary timing of such interventions.

\section{NO and inhibition of cell death}

In addition to the contribution of NO to neuronal cell death described above, it is important to outline the mechanisms whereby NO-related species can also be neuroprotective. Recent work has suggested that S-nitrosylation of critical cysteine sulfhydryl groups of the NMDA receptor, of p21ras during MAP kinase signaling, and in the active site of caspase enzymes can decrease the activity of these proteins, thereby contributing to neuroprotection. For example, curtailing excessive activity of the NMDA receptor by S-nitrosylation is neuroprotective..$^{2-4}$ Similarly, downstream from NMDA receptor activation, S-nitrosylation of a critical cysteine residue in p21ras or of the cysteine residue in the active site of all known caspase enzymes decreases their activity and also affords protection to neurons from NMDA receptormediated apoptotic events. ${ }^{16-18}$ Thus, depending on its redox state, the NO group can contribute to excitotoxicity (via formation of peroxynitrite in conjunction with superoxide anion) or provide neuroprotection (by down-regulating the activity of both the NMDA receptor and its downstream activation of p21ras and caspases).

Besides directly inhibiting p21ras and caspases, NO may interfere with the execution of apoptosis at different steps, without necessarily affecting the rate of cell death (e.g., by changing the mode of demise from apoptosis to necrosis). ${ }^{17}$ For example, NO can inhibit caspase activation by mechanisms in addition to S-nitrosylation, for example, by NO-dependent formation of cGMP that can interfere with cell death signaling upstream from caspase activation. ${ }^{19-21}$ Moreover, since a well documented action of $\mathrm{NO}$ is inhibition of the mitochondrial respiratory chain, it seems conceivable that the resulting ATP-depletion might be relevant to the effects of $\mathrm{NO}$ on cell death. In fact, recent results have suggested that NO prevents caspase activation by inhibiting mitochondrial respiration, and thereby lowering intracellular ATP levels (Leist et al, submitted). The prevention of cell death in this system is only ephemeral. Cell demise is delayed, and doomed cells die eventually by necrosis. When non-mitochondrial, glycolytic ATP generation was supported via glucose supplementation to the culture medium, death reverted to its apoptotic form.

In vivo, halting the apoptotic program may have two possible implications: (1) neurons protected by NO via stopping the apoptotic execution cascade would have time to recover from a transient or mild insult, and thus survive; or (2) neurons exposed to a lethal, normally apoptotic insult would eventually lyse without being removed by phagocytosis. Thus, depending on the situation, endogenous mediators, such as NO, either may prevent cell demise entirely or convert an apoptotic insult into a necrotic one. In the latter case, the release of factors from dead cells and the ensuing inflammation would further aggravate tissue damage.

\section{Cysteine sulfhydryls react with NO-related species}

As alluded to above, may of the neuroprotective actions of 'NO' are mediated by S-nitrosylation of proteins critical for neuronal survival. A key question is determining the life or death outcome concerns the mechanism and conditions that favor this reaction. This section outlines some of those conditions. Free endogenous nitrosonium $\left(\mathrm{NO}^{+}\right)$exists only at low $\mathrm{pH}$. However, functional equivalents of $\mathrm{NO}^{+}$can be transferred to thiol, or more properly perhaps, thiolate anion $\left(\mathrm{RS}^{-}\right)$, at physiological $\mathrm{pH}$. For example, transfer of $\mathrm{NO}^{+}$ equivalents occurs from one nitrosothiol to another, a reaction termed transnitrosylation, i.e., $\mathrm{R}-\mathrm{SH}+\mathrm{R}^{\prime}-\mathrm{SNO} \rightleftarrows \mathrm{R}-\mathrm{SNO}+\mathrm{R}^{\prime}-$ $\mathrm{SH}$. Since transfer of $\mathrm{NO}^{+}$involves thiolate anion $\left(\mathrm{R}^{-} \mathrm{S}^{-}\right.$), it is $\mathrm{pH}$ dependent. $^{22}$ Endogenous nitrosothiols, such as Snitrosoglutathione, have been demonstrated to react in this manner and to exist in brain and in lung at concentrations approaching tens of micromolar. ${ }^{22-24}$ Additionally, recent evidence has shown that nNOS can, in conjunction with glutathione, produce S-nitrosoglutathione, ${ }^{25}$ an $\mathrm{NO}^{+}$equivalent and endogenous donor. The enzymatic machinery underlying the formation and breakdown of nitrosothiols is just beginning to be characterized. For example, thioredoxin reductase was shown to catalyze the homolytic cleavage of nitrosothiol (R-SNO) to nitric oxide $\left(\mathrm{NO}^{\bullet}+\mathrm{RS}^{\bullet}\right) .^{26}$

Classically, there was no precedent for direct reaction of $\mathrm{NO}{ }^{\bullet}$ with thiols under anaerobic conditions. ${ }^{27,28}$ Recently, however, Ischiropoulos and co-workers demonstrated that under particular conditions, e.g., in the presence of an electron acceptor such as $\mathrm{O}_{2}, \mathrm{NO}^{\bullet}$ could react with thiol to form a nitrosothiol. ${ }^{29}$ However, this reaction may have been artificially facilitated by nominal amounts of copper that contaminated the solutions ( $\mathrm{J}$ Beckman, personal communication). Thus, the consensus opinion is that the reaction of $\mathrm{NO}^{\bullet}$ with thiol does not proceed directly, as previously thought. In any event, the reaction of $\mathrm{NO}^{\bullet}$ and $\mathrm{O}_{2}{ }^{--}$to form peroxynitrite is kinetically favored if both of these reactants are present. $^{30}$

Another important concept in considering the possible chemical reactions of the NO group involves our image of the local diffusion and ephemeral nature of $\mathrm{NO}^{\bullet}$. Recently, David Bredt and colleagues demonstrated that nNOS is located in close proximity to potential targets of $\mathrm{NO}$ by virtue of its PDZ domain. ${ }^{31}$ For example, nNOS interacts via its PDZ domain with the carboxyl-terminal tail of NR1, the subunit of the NMDA receptor that is essential for functional activity. Therefore, restricted diffusional constraints and the need for high local concentrations to facilitate NO reactions should not present a problem.

With some of the chemical reactions of these NO-related species in hand, we now turn our attention to the mechanism of S-nitrosylation or transfer of the NO moiety to cysteine sulfhydryl groups on the NMDA receptor. In the six years since we first proposed that S-nitrosylation can modulate protein function using the NMDA receptor as the archetypal protein, ${ }^{4}$ S-nitrosylation has also been shown to regulate the activity of various other ion channels, Gproteins, growth factors, enzymes, and transcription factors. $^{2}$ These reactions of NO-related species do not 
involve the well-known activation of guanylate cyclase by reaction with heme to increase cGMP formation. Rather they involve reactions with cysteine sulfhydryls on an increasing number of protein targets to provide modulation of function, analogous to phosphorylation of critical serine, threonine, or tyrosine residues. S-Nitrosylation may be more versatile than phosphorylation in regulating protein activity since S-nitrosylation can occur on either extracellular or intracellular cysteine sulfhydryl groups, whereas phosphorylation and similar post-translational events are exclusively intracellular. The chemical reactivity of NOrelated species is related to the local redox milieu and peptide environment, $\mathrm{pH}$, temperature, and the presence of catalytic amounts of transition metals.

Previously, we had suggested that reaction of the NO group with regulatory sulfhydryl(s) of the NMDA receptor's redox modulatory site(s) results in downregulation of receptor activity. ${ }^{4}$ In addition to our group, other groups had also shown that NO donors could decrease NMDA function, ${ }^{32-34}$ but the exact mechanism of the reaction has remained contentious. ${ }^{35}$ The redox basis for this reaction will be presented below for both endogenous and recombinant NMDA receptors.

\section{S-nitrosylation, NMDA receptor activity, and neuroprotection}

We believe that the NO group can decrease NMDA receptor activity, ${ }^{32,33,36}$ at a redox modulatory site(s) of the receptor, consisting of critical cysteine sulfhydryls or thiol groups. ${ }^{4,33,37,38}$ In native neurons (e.g. cerebrocortical cells), we measured the amplitude of NMDA-evoked responses, monitored by whole-cell and single-channel recording with a patch electrode or by digital calcium imaging with the $\mathrm{Ca}^{2+}$ sensitive dye fura-2. ${ }^{4,33}$ We found that sulfhydryl reducing agents, such as dithiothreitol (DTT) which promote the formation of free thiol groups, increased NMDA responses, predominantly by increasing the opening frequency of NMDA receptor-operated channels. In contrast, oxidizing agents, such 5,5'dithio(2-bisnitrobenzoic acid) (DTNB) decreased NMDA responses, by forming thiobenzoate protein conjugates at single sulfhydryl groups or perhaps by facilitating disulfide bond formation. Additionally, taken together with the DTT and DTNB results, we knew that thiols on the NMDA receptor were involved because under our conditions $\mathrm{N}$-ethylmaleimide (NEM), a relatively specific agent for alkylating thiols, irreversibly blocked the effects of these redox reagents while itself slightly decreasing responses to NMDA. 4,33 Importantly, under our specific conditions, NEM also prevented the subsequent effects of $\mathrm{NO}$ donors, indicating that reactions of thiol and NO groups were involved. Recently, both our group and that of Joël Bockaert $^{34}$ have also demonstrated that endogenous production of NO can decrease NMDA receptor activity, indicating the potential physiological importance of this effect. In these experiments implicating the involvement of endogenous NO, inhibition of NOS was found to enhance subsequent NMDA receptor responses. Heretofore, however, there has not been universal consensus on the mechanism of action of $\mathrm{NO}$ in this system.
As an example of an $\mathrm{NO}^{+}$chemical reaction at the NMDA receptor, we found that S-nitrosocysteine decreases NMDA receptor activity as demonstrated by whole-cell recording or by digital calcium imaging. ${ }^{4}$ During singlechannel recording, S-nitrosocysteine (SNOC) decreased the opening frequency of NMDA receptor-operated channels in outside-out patches from cerebrocortical neurons. ${ }^{39}$ In the presence of copper, zinc-superoxide dismutase (Cu,Zn-SOD), SNOC attenuated NMDA-evoked $\mathrm{Ca}^{2+}$ influx, a prerequisite for NMDA receptor-mediated neurotoxicity. Not surprisingly therefore, under the same conditions, application of SNOC ameliorated NMDA receptor-mediated neurotoxicity. These findings can be explained best by SNOC donating $\mathrm{NO}^{+}$equivalents. Thus, S-nitrosylation or facile transfer of an $\mathrm{NO}^{+}$equivalent to thiol groups of the NMDA receptor results in a nitrosothiol derivative of the NMDA receptor, which decreases receptor activity. Under these conditions, any $\mathrm{NO}^{\bullet}$ produced by alternative homolytic cleavage of SNOC is prevented from entering a neurotoxic pathway of peroxynitrite formation $\left(\mathrm{ONOO}^{-}\right)$via reaction with $\mathrm{O}_{2}^{\bullet-}$ because of the presence of excess SOD. ${ }^{3,4}$ Rather, NO group transfer leads to down-regulation of NMDA receptor activity, possibly through facilitation of disulfide formation. The fact that EDTA can prevent the effects of the NO group on NMDA receptor activity ${ }^{35}$ supports rather than refutes this chemistry. In particular, metals can facilitate nitrosative reactions involving $\mathrm{NO}^{\circ}$ and $\mathrm{O}_{2}{ }^{1,40}$ In general, nitrosation of redox sites is facilitated by oxygen, transition metals, and perhaps $\mathrm{O}_{2}{ }^{\bullet-}$ (superoxide anion). ${ }^{6,29}$ The common event is transfer of an $\mathrm{NO}^{+}$equivalent or another intermediate with $\mathrm{NO}^{+}$-like character to form an RS-NO, in this case on the NMDA receptor.

\section{S-nitrosylation of recombinant NMDA receptors}

In order to better understand redox mechanisms postulated to exist based on the above experiments on primary neurons with native NMDA receptors, we have turned to recombinant systems. Our work on nitrosylation and other redox reactions of recombinant NMDA receptors in the Xenopus oocyte expression system is instructive but also must be interpreted with a degree of caution. ${ }^{38,41}$ We do not yet appreciate how to form recombinant NMDA receptors that exactly mimic native receptors and therefore conclusions based on site-directed mutagenesis studies of cysteine residues must be viewed with tempered enthusiasm. In fact, in the course of performing PCR reactions based on primers containing the cysteines known to be unique to NMDA receptor subunits, our group discovered a new NMDA receptor subunit (originally termed NMDAR-L or $\chi^{-1}$, but more recently named NR3A). ${ }^{42-44}$ Additional unidentified NMDAR subunits probably remain to be identified. Thus, it is not yet possible to definitively understand native NMDA receptor responses based on recombinant subunits. This statement notwithstanding, our data show that the cysteines at position 744 and 798 are not only important to redox reactions in general, but also have some (albeit minor) influence on the effect of $\mathrm{NO}$ and $\mathrm{Zn}^{2+}$ on the NMDA receptor; however, this can only be seen after 
chemical reduction of the receptor with DTT because of disulfide bond formation at this site (two cysteine residues on GluR2, which are homologous to Cys 744 and Cys 798 of NR1, were also recently shown to form a disulfide bond ${ }^{45}$ ). Aizenman et $a{ }^{46}$ did not chemically reduce the NMDA receptor and thus failed to see the effect of S-nitrosylation at cysteine residues 744 and 798 of NR1. In an extensive series of experiments using site-directed mutagenesis of all cysteines on the known NMDAR subunits, we found that additional cysteine residues on the NR2A subunit contribute in a more important manner to the NO effect than Cys 744 and Cys 798 of NR1, indicating that the NMDAR is polynitrosylated to modulate its physiological function in a manner resembling the ryanodine receptor. ${ }^{47}$ In brief, our site-directed mutagenesis results show that (1) specific NMDA receptor subunit combinations manifest larger NO-induced decreases in activity than other receptor subunit combinations (e.g., a greater effect NO is observed for NR1/NR2A than NR1/NR2B receptors), ${ }^{41,48}$ and (2) seven cysteine residues on NR1 and NR2A mediate the effects of $\mathrm{NO}, \mathrm{Zn}^{2+}$, or redox agents on the NMDA receptor; six of these cysteine residues work in pairs, i.e., apparently forming three disulfide bonds after exposure to oxidizing agents or, in the case of four of these cysteine residues, after reaction with $\mathrm{NO}^{+}$donors. One additional cysteine residue appears to be S-nitrosylated only and does not apparently form a disulfide. The effects of NO group transfer would be expected to be either relatively long lasting (in the case of disulfide formation) or more transient (in the case of reaction with a single thiol), and indeed both such effects have been observed on primary neurons. While it appears that the $\mathrm{NO}$ effects are predominantly due to reaction with the single cysteine sulfhydryl on the NR2A subunit, the four other cysteine residues also contribute somewhat by reacting with $\mathrm{NO}^{+}$, but only if they are in the reduced state (Y-B Choi, H-SV Chen, and SA Lipton, unpublished observation). In contrast, the voltage-independent effects of $\mathrm{Zn}^{2+}$ on NR1/NR2A receptors are influenced by all of the aforementioned six cysteine residues that act in pairs and whose redox status can be modulated by DTT and DTNB.

Other effects of 'NO' are of course not ruled out by these findings. It is also true that the effects of $\mathrm{Zn}^{2+}$ on the NMDA receptor and that of redox agents can be confused because some reducing agents (such as DTT) bind $\mathrm{Zn}^{2+}$, because EDTA chelates $\mathrm{Zn}^{2+}$, and because $\mathrm{Zn}^{2+}$ may also be coordinated, at least in part, by cysteine residues. It had been proposed that $\mathrm{NO}$ can react with a $\mathrm{Zn}^{2+}$ site of the NMDA receptor by Joël Bockaert's group. ${ }^{35}$ However, we can now explain all of these previous findings with our more recent work showing that the effect of $\mathrm{Zn}^{2+}$ can be influenced by the redox state of the six cysteine residues on the NMDAR that are discussed above, four of which can also react with $\mathrm{NO}^{+}$. Hence, it appears that at least some sites of $\mathrm{NO}^{+}$and $\mathrm{Zn}^{2+}$ action may share common cysteine residues.

\section{Nitroglycerin decreases NMDA receptor activity and attenuates neurotoxicity}

Based on the above findings, the ideal NO group donor drug would be one that reacts readily with critical thiol groups of the NMDA receptor to inhibit excessive $\mathrm{Ca}^{2+}$ influx but does not produce $\mathrm{NO}^{\bullet}$ to react with $\mathrm{O}_{2}^{\bullet-}$ so it will not lead to the formation of peroxynitrite $\left(\mathrm{ONOO}^{-}\right)$. We therefore studied nitroglycerin (NTG) as an exemplary compound. Specifically, alkyl nitrates such as NTG do not directly liberate nitric oxide (NO ${ }^{\circ}$ ) to any significant extent; rather, they react readily with thiol groups forming derivative thionitrites (RS-NO) or thionitrates (RS- $\mathrm{NO}_{2}$ ) (together, these are represented as $\mathrm{RS}-\mathrm{NO}_{\mathrm{x}}, \mathrm{x}=1$ or 2 ; Figure 1). ${ }^{4,33}$ Using whole-cell recording with patch clamp electrodes and digital calcium imaging with fura-2 on primary cerebrocortical neurons, we found that NTG inhibited NMDA-evoked currents and $\mathrm{Ca}^{2+}$ influx. ${ }^{4,33}$ Strong evidence that this effect of NTG is mediated by its reactions with thiol in the above-illustrated manner came from a series of chemical experiments. These studies showed that under our conditions specific alkylation of thiol groups with NEM completely abrogated the inhibitory effect of NTG on subsequent NMDA-evoked responses. ${ }^{33}$

The finding that NTG could inhibit NMDA-evoked responses was consistent with the demonstration that similar concentrations of NTG could also significantly ameliorate NMDA-induced neuronal killing in cerebrocortical cultures. ${ }^{4,33}$ Additional in vivo data show that high doses of nitroglycerin are neuroprotective in rat models of

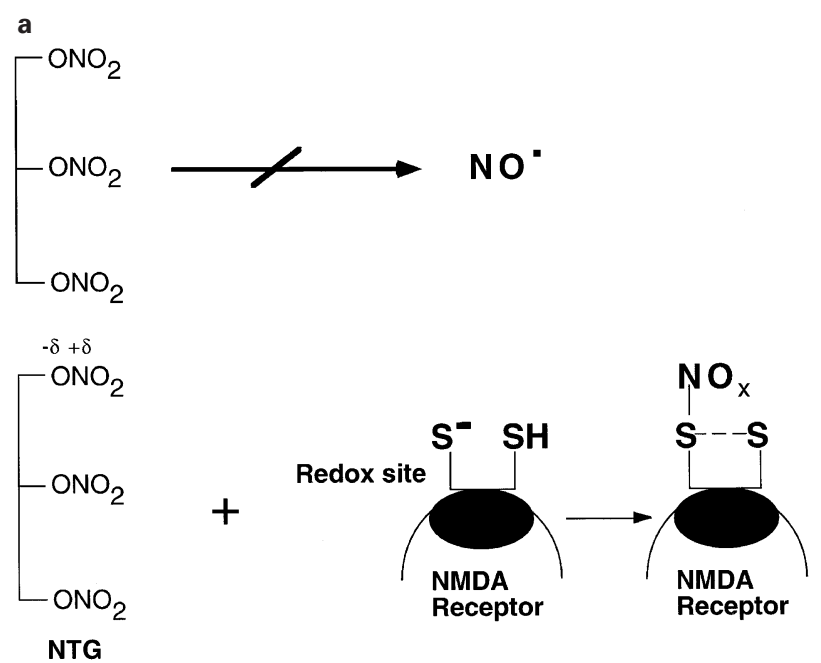

b

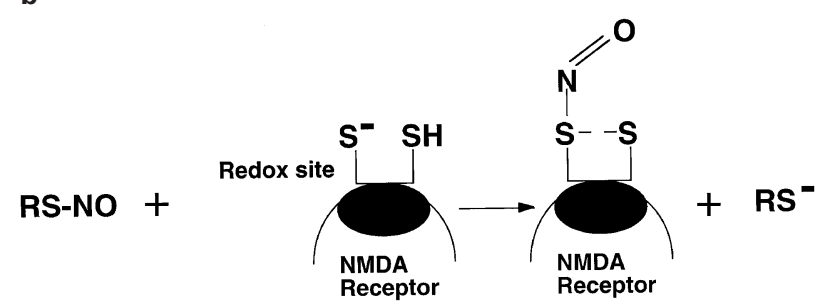

Figure 1 Schematic model of S-ntirosylation of the NMDA receptor Chemical mechanism of action of nitroglycerin (NTG) with thiol groups (a) and S-nitrosocysteine (an RS-NO) with thiol groups (b) on the NMDA receptor. NTG itself does not directly generate nitric oxide NO*. Instead, NTG transfers $\mathrm{NO}^{+}$(where $\mathrm{x}=1$ or 2 ) to critical thiol groups of NMDA receptor cysteine residues (in some cases this may facilitate disulfide bond formation, indicated by a dashed line). In the case of RS-NO, $\mathrm{NO}^{+}$is transferred to thiol. This reaction results in decreased activity of NMDA receptor-operated channels 
focal ischemia under conditions of constant systemic blood pressure and modestly increased cerebral blood flow in the penumbra. ${ }^{49}$ These parameters are held stable either by inducing tolerance to the systemic effects of NTG through chronic transdermal application, ${ }^{50}$ or by intravenous infusion of a pressor agent concurrently with nitroglycerin. ${ }^{49}$ Although difficult to prove in vivo, it appears likely that the decrease in stroke size observed after treatment with NTG is at least in part due to its effect on decreasing NMDA receptor activity although several other beneficial actions also occur. ${ }^{49}$

\section{S-nitrosylation of caspases}

As introduced earlier, another example of beneficial NTG and S-nitrosylation reactions that can prevent neuronal cell death involves caspases. Caspases are members of the interleukin$1 \beta$-converting enzyme (ICE)-CED-3 protease family of enzymes that play a crucial role in mammalian apoptosis during development or due to growth factor deprivation. Additionally, caspases have been recently implicated in the pathway to neuronal apoptosis from mild excitotoxic insults. $^{16,51}$ More intense excitotoxic injuries evoke rapid and irreversible energy compromise, leading to the failure of ionic homeostasis with consequent swelling and lysis; ${ }^{14,52}$ this form of cell death represents necrosis and is not dependent on caspases. ${ }^{51}$ One new regulatory pathway of caspase activity involves S-nitrosylation. In a recent development in the apoptosis field, in primary neurons ${ }^{16}$ and in other cells, ${ }^{17,53,54}$ caspase activity has been found to be decreased by S-nitrosylation or transfer of an $\mathrm{NO}^{+}$-like group to a critical cysteine sulfhydryl that is located in the active site in all caspase enzymes. This finding has important implications for the regulation of apoptosis by the NO group: under specific redox conditions that favor nitrosylation of caspases, apoptosis can be attenuated by decreasing caspase activity, whereas conditions favoring the generation of $\mathrm{NO}^{\bullet}$ will lead, via reaction with $\mathrm{O}_{2}^{\bullet-}$, to the production of peroxynitrite $\left(\mathrm{ONOO}^{-}\right)$and consequent cell death (either apoptotic or necrotic depending on the intensity of the insult).

\section{A variety of targets for S-nitrosylation}

After NMDA receptor activity was shown to be regulated by NO-related species, similar data were presented for the $\mathrm{Ca}^{2+}$. activated $\mathrm{K}^{+}$channel of cardiac muscle. ${ }^{55}$ In this case, donors of $\mathrm{NO}^{+}$equivalents were shown to activate the channel, and, similar to findings at the NMDA receptor in our laboratory, NEM blocked the effect by irreversibly alkylating thiol groups. Along similar lines, several other ion channels, enzymes, Gproteins, transcription factors, and other proteins are either up-regulated or down-regulated by similar mechanisms of Snitrosylation or donation of $\mathrm{NO}^{+}$equivalents to regulatory sulfhydryl centers. $^{2}$ The list will undoubtedly grow just as in recent years phosphorylation, myristolation, and palmitoylation have become recognized as important biochemical processes for regulatory function. Interestingly, palmitoylation may be aimed at similar critical thiol group targets, resulting in thioester bond formation. In fact, on some proteins such as SNAP-25 it is possible that S-nitrosylation and palmitoylation may compete for the same sulfhydryl group, possibly with different physiological outcomes. ${ }^{56}$

In contrast to better-known intracellular regulatory processes such as phosphorylation, S-nitrosylation of critical cysteine residues can occur extracellularly, intracellularly, or possibly even within the putative membrane spanning region of a protein. From this point of view, Snitrosylation may offer additional versatility in the location of control that can be exerted compared to phosphorylation and other better known post-translational forms of modification.

\section{Proposed consensus motif for S-nitrosylation}

The primary amino acid sequence of functionally important sites for post-translational modification of proteins are distinguished by the occurrence of certain patterns or motifs. In many cases such motifs constitute only a very minor part of the entire protein primary sequence. Thus, small patterns often are not detected by overall alignment of protein sequences that are only distantly or not at all related. Such motifs, however, can be identified by the occurrence of a particular cluster of residue types in the primary sequence. A collection of such sequence fingerprints has been developed for PROSITE, a database of biologically significant sites and patterns that can be used to identify families of functionally related proteins or sites for post-translational modification. Examples of such motifs are the consensus sequence patterns required for glycosylation or phosphorylation.

In an attempt to define a possible consensus motif that might be required or at least be facilitatory for Snitrosylation, in collaboration with the laboratories of Nikolaus Sucher and Jonathan Stamler, we initially examined the putative target sites for redox modulation of NMDA receptors. Most importantly, cysteine residues in similar motifs to that described below for the NMDA receptor have been shown by various chemical criteria to be nitrosylated on proteins such as hemoglobin, p2 $1^{\text {ras }}$, cyclooxygenase and others. ${ }^{2}$ As discussed above, two cysteines (abbreviated $C$ in the single letter amino acid code) in the NR1 subunit have been found by site-directed mutagenesis to be necessary for the persistent component of redox modulation of that receptor ${ }^{38}$ and in the reduced state they can be S-nitrosylated (Choi et al, submitted). Unexpectedly, however, these cysteines, C744 and C798, appear to be conserved in all ionotropic glutamate receptors when the sequences are aligned by overall homology. ${ }^{42,57}$ Nonetheless, among the ionotropic glutamate receptors, only NMDA receptors are exquisitely sensitive to redox modulation and ' $N O$ ' effects. ${ }^{33,58}$ Inspection of the immediate amino acid neighbors of these cysteines revealed that the NR1 cysteines are distinguished from the cysteines conserved in the other ionotropic glutamate receptors in that they are preceded at position -2 by a polar amino acid (G,S,T,C,Y,N,Q), an acidic $(D, E)$ or basic $(K, R, H)$ amino acid at position -1 , and an acidic amino acid at position +1 . Based on this observation, we constructed the degenerate amino acid pattern designated $(\mathrm{G}, \mathrm{S}, \mathrm{T}, \mathrm{C}, \mathrm{Y}, \mathrm{N}, \mathrm{Q})(\mathrm{K}, \mathrm{R}, \mathrm{H}, \mathrm{D}, \mathrm{E}) \mathrm{C}(\mathrm{D}, \mathrm{E})$ in 
standard single letter amino acid code and used it in a search of the Protein Identification Resource (PIR) and Swiss Protein (SW) databases with the program Findpatterns of the GCG software package (Program Manual for the Wisconsin Package, Version 8, September 1994, Genetics Computer Group, 575 Science Drive, Madison, Wisconsin, 53711 USA). In the PIR database (Release 44.0; March 1995), 3878 sequences out of 77573 contained this pattern at least once, in the SW database (Release 31.0; March 1995), 2383 out of 43470 sequences contained this pattern. Viral, bacterial, plant and animal sequences contained this motif.

Among candidates for regulation by S-nitrosylation that were identified by the database search were ion channels (NMDA receptor, voltage sensitive $\mathrm{Na}^{+}$channel, cyclic nucleotide-gated channel), transporters (Ca-ATPase, Ktransporter), receptors (inositol trisphosphate receptor, nerve growth factor receptor), enzymes (oxidoreductases, dehydrogenases, adenylate and guanylate cyclases, proteases, DNA topoisomerases, DNA and RNA polymerases, kinases, phosphatases), transcription factors (helix loop helix proteins, NF- $\kappa \mathrm{B}$, zinc finger proteins), small GTP binding proteins (rab, ras, sas, ypt), cell adhesion molecules (integrins, neural cell adhesion molecule), cell adhesion substrates (laminin, collagen), cyclins and coagulation factors (IXa, Xa, XIII).

In fact, 20 out of 27 proteins that had been listed in a recent review ${ }^{6}$ as bioregulatory targets of nitrosylation contain the full motif. The presence of the putative nitrosylation motif in guanylate cyclase suggests that the NO-group may regulate the functional activity of guanylate cyclase by S-nitrosylation in addition to the interaction with the heme group of this enzyme. It is possible, however, that S-nitrosylation might occur at sites other than the proposed motif or that the motif may only be evident in the tertiary rather than the primary structure of some proteins. Moreover, it appears that a certain subset of the motif (basic amino acid residuecysteine residue-acidic residue) may bear the highest statistical correlation to the propensity for nitrosylation. ${ }^{2}$ While the proposed motif was defined post-hoc based on our results with redox modulation of the NMDA receptor, it should allow us to identify additional possible target proteins for S-nitrosylation. Most importantly, this motif predicts a target sequence that can be subjected to site directed mutagenesis in order to experimentally verify its importance for S-nitrosylation.

\section{Proposed nitroxyl $\left(\mathrm{NO}^{-}\right)$reactions with cysteine thiol}

It has been proposed that $\mathrm{NO}^{-}$can be generated in two forms, $\mathrm{NOH}$ or $\mathrm{HNO}$, both of which may exist in the triplet or singlet states. ${ }^{59,60}$ For example, in the singlet state, two antibonding electrons occupy a single outer $\Pi^{*}$ (pi antibonding molecular orbital), with spins opposed. In the triplet state the two $\Pi^{*}$ antibonding orbitals each contain an electron with spins aligned (with a $z$-component of electron spin of $+1,0$, or -1 ; hence, the designation 'triplet state'). In the singlet state, we have found evidence that $\mathrm{NO}^{-} / \mathrm{HNO}\left(\mathrm{pK}_{\mathrm{a}} 4.7\right)$ can react

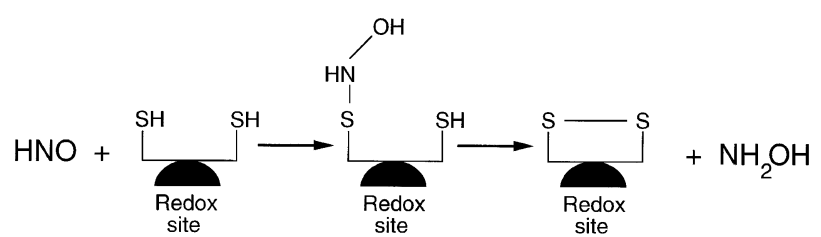

Figure 2 Schematic model of reaction of nitroxyl $\left(\mathrm{NO}^{-}\right)$with the NMDA receptor. In the singlet state, $\mathrm{NO}^{-}$can react with critical thiols of the NMDA receptor to yield an $\mathrm{R}-\mathrm{SNH}-\mathrm{OH}$ derivative, possibly proceeding to disulfide formation

with critical thiols of the NMDA receptor to yield either an R$\mathrm{SNH}-\mathrm{OH}$ derivative or possibly a disulfide, in which case hydroxylamine $\left(\mathrm{NH}_{2} \mathrm{OH}\right)$ is also formed (Figure 2). ${ }^{22,61}$ These reactions decrease NMDA receptor activity.,4

\section{Conclusions}

Possible chemical reactions of the NO group are dictated by its redox state. In the case of $\mathrm{NO}^{+}$equivalents, this mechanism appears to involve S-nitrosylation and possibly further oxidation of critical thiols to disulfide bonds on the NMDA receptor to decrease channel activity; a cysteine residue, known to be present in the active site of all known caspase enzymes, can also be S-nitrosylated, resulting in inhibition of enzyme activity. These effects of S-nitrosylation, and undoubtedly others, can lead to neuroprotection by 'NO donors', such as NTG, which favor S-nitrosylation or related reactions. In contrast, $\mathrm{NO}^{\bullet}$ kinetically prefers to react with $\mathrm{O}_{2}{ }^{--}$to yield peroxynitrite $\left(\mathrm{ONOO}^{-}\right)$, which is neurodestructive.

It is becoming increasingly evident that in addition to NMDA receptors and caspase enzymes, biological activities of many other proteins containing critical cysteine residues can be regulated by S-nitrosylation and other redox reactions, in a sense similar to the type of control exerted by phosphorylation. ${ }^{4}$ This type of chemical reaction may represent a new and ubiquitous pathway for the molecular control of protein function by potentially reactive sulfhydryl centers.

\section{Acknowledgments}

This review is based upon work performed in a close collaboration between the laboratories of Stuart Lipton at Harvard Medical School, Jonathan Stamler at Duke Medical Center, Pierluigi Nicotera at the University of Konstanz (Germany), and Nikolaus Sucher at the Hong Kong University of Science and Technology. We are grateful to many members of our laboratories who contributed. The work was presented at several recent meetings, and this is reflected in the proceedings of these meetings.

\section{References}

1. Stamler JS, Singel DJ and Loscalzo J (1992) Biochemistry of nitric oxide and its redox activated forms. Science 258: $1898-1902$

2. Stamler JS, Toone EJ, Lipton SA and Sucher NJ (1997) (S)NO signals: Translocation, regulation, and a consensus motif. Neuron 18: 691-696 
3. Lipton SA and Stamler JS (1994) Actions of redox-related congeners of nitric oxide at the NMDA receptor. Neuropharmacology 33: 1229-1233

4. Lipton SA, Choi Y-B, Pan Z-H, Lei SZ, Chen H-SV, Sucher NJ, Loscalzo J, Singe DJ and StamlerJS (1993) A redox-based mechanism for the neuroprotective and neurodestructive effects of nitric oxide and related nitroso-compounds. Nature 364: $626-632$

5. Dawson TM, Dawson VL and Snyder SH (1992) A novel neuronal messenger molecule in brain: the free radical, nitric oxide. Ann. Neurol. 32: 297-311

6. Stamler JS (1994) Redox signaling: nitrosylation and related target interactions of nitric oxide. Cell 78: $931-936$

7. Dawson VL, Dawson TM, London ED, Bredt DS and Snyder SH (1991) Nitric oxide mediates glutamate neurotoxicity in primary cortical cultures. Proc. Natl. Acad. Sci. USA 88: 6368-6371

8. Noronha-Dutra AA, Epperlein MM and Woolf N (1993) Reaction of nitric oxide with hydrogen peroxide to produce potentially cytotoxic singlet oxygen as a model for nitric oxide-mediated killing. FEBS Lett. 321:59-62

9. Rothman SMand OIney JW (1987) Excitotoxicity and the NMDA receptor. Trends Neurosci. 10: 299-302

10. Choi DW (1988) Glutamate neurotoxicity and diseases of the nervous system. Neuron 1: 623-634

11. Meldrum B and Garthwaite J (1990) Excitatory amino acid neurotoxicity and neurodegenerative disease. Trends Pharmacol. Sci. 11: 379-387

12. Coyle JT and Puttfarken P (1993) Oxidative stress, glutamate and neurodegenerative disorders. Science 262: 689-695

13. Lipton SA and Rosenberg PA (1994) Mechanisms of disease: Excitatory amino acids as a final common pathway for neurologic disorders. N. Engl. J. Med. 330: 613-622

14. Bonfoco E, Krainc D, Ankarcrona M, Nicotera P and Lipton SA (1995) Apoptosis and necrosis: two distinct events induced respectively by mild and intense insults with NMDA or nitric oxide/superoxide in cortical cell cultures. Proc. Natl. Acad. Sci. USA 92: 7162-7166

15. Beckman JS, Beckman TW, Chen J, Marshall PA and Freeman BA (1990) Apparent hydroxyl radical production by peroxynitrite: implications for endothelial injury from nitric oxide and superoxide. Proc. Natl. Acad. Sci. USA 87: $1620-1624$

16. Tenneti L, D'Emilia DM and Lipton SA (1997) Suppression of neuronal apoptosis by $S$-nitrosylation of caspases. Neurosci. Lett. 236: 139-142

17. Melino G, Bernassola F, Knight RA, Corasaniti MT, Nisticò G and Finazzi-Agrò $A$ (1997) S-nitrosylation regulates apoptosis. Nature 388: 432-433

18. Yun H-Y, Gonzalez-Zulueta M, Dawson VL and Dawson TM (1998) Nitric oxide mediates $N$-methyl-D-aspartate receptorinduced activation of $21^{\text {ras }}$. Proc. Natl. Acad. Sci. USA 95: 5773-5778

19. Mannick JB, Asano K, Izumi K, Kleff E and Stamler JS (1994) Nitric oxide produced by human $B$ lymphocytes inhibits apoptosis and Epstein-Barr virus reactivation. Cell 79: 1137-1146

20. Kim Y-M, Talanian RV and Billiar TR (1997) Nitric oxide inhibits apoptosis by preventing increases in caspase-3-like activity via two distinct mechanisms. J. Biol. Chem. 272: 31138-31148

21. Hebesteit H, Dibbert B, Balatti I, Braun D, Schapowal A, Blaser K and Simon H-U (1998) Disruption of fas receptor signaling by nitric oxide in eosinophils. J. Exp. Med. 187: 415-425

22. Arnelle DR and Stamler JS (1995) $\mathrm{NO}^{+}, \mathrm{NO}$, and $\mathrm{NO}^{-}$donation by $S_{-}$ nitrosothiols: Implications for regulation of physiological functions by $S$ nitrosylation and acceleration of disulfide formation. Arch. Biochem. Biophys. 318: $279-285$

23. Hogg N, Singh RJ and Kalyanaraman B (1996) The role of glutathione in the transport and catabolism of nitric oxide. FEBS Lett. 382: 223-228

24. Kluge I, Gutteck-Amsler U, Zollinger M and Do KQ (1997) S-nitrosoglutathione in rat cerebellum: identification and quantification by liquid chromatography-mass spectrometry. J. Neurochem. 69: 2599-2607

25. Mayer B, Pfeiffer S, Schrammel A, Koesling D, Schmidt Kand Brunner F (1998) A new pathway of nitric oxide/cyclic GMP signaling involving S-nitrosoglutathione. J. Biol. Chem. 273: 3264-3270

26. Nikitovic D and Holmgren A (1996) S-nitrosoglutathione is cleaved by the thioredoxin system with liberation of glutathione and redox regulating nitric oxide. J. Biol. Chem. 271: 19180-19185

27. Pryor WA and Lightsey JW (1981) Mechanisms of nitrogen dioxide reactions: initiation of lipid peroxidation and the production of nitrous acid. Science 214: 435-437
28. Pryor WA, Church DF, Govinden CK and Crank G (1982) Oxidation of thiols by nitric oxide and nitrogen dioxide: synthetic utility and toxicological implications. J. Org. Chem. 47: 156-159

29. Gow AJ, Buerk DG and Ischiropoulos H (1997) A novel reaction mechanism for the formation of S-nitrosothiol in vivo. J. Biol. Chem. 272: 2841-2845

30. Beckman JS (1994) in The Biological Chemistry of Nitric Oxide Lancaster J eds. (Academic Press San Diego, CA)

31. Brenman JE, Chao DS, Gee SH, McGee AW, Craven SE, Santilliano DR, Wu Z, Huang F, Xia H, Peters MF, Froehner SC and Bredt DS (1996) Interaction of nitric oxide synthase with the postsynaptic density protein PSD-95 and $\alpha 1$-syntrophin mediated by PDZ domains. Cell 84: 757-767

32. Manzoni O, Prezeau L, Marin P, Deshager S, Bockaert J and Fagni L (1992) Nitric oxide-induced blockade of NMDA receptors. Neuron 8: 653-662

33. Lei SZ, Pan Z-H, Aggarwal SK, Chen H-SV, Hartman J, Sucher NJ and Lipton SA (1992) Effect of nitric oxide production on the redox modulatory site of the NMDA receptor-channel complex. Neuron 8: 1087-1099

34. Manzoni $O$ and Bockaert J (1993) Nitric oxide synthase activity endogenously modulates NMDA receptors. J. Neurochem. 61: 368-370

35. Fagni L, Olivier M, Lafon-Cazal M and Bockaert J (1995) Involvement of divalent ions in the nitric oxide-induced blockade of $\mathrm{N}$-methyl-D-aspartate receptors in cerebellar granule cells. Mol. Pharmacol. 47: 1239-1247

36. Hoyt KR, Tang L-H, Aizenman E and Reynolds IJ (1992) Nitric oxide modulates NMDA-induced increases in intracellular $\mathrm{Ca}^{2+}$ in cultured rat forebrain neurons. Brain Res. 592: 310-316

37. Kohr G, Eckardt, S, Lüddens H, Monyer H and Seeburg PH (1994) NMDA receptor channels: subunit-specific potentiation by reducing agents. Neuron 12: $1031-1040$

38. Sullivan JM, Traynelis SF, Chen H-SV, EscobarW, Heinemann SF and Lipton SA (1994) Identification of two cysteine residues that are required for redox modulation of the NMDA subtype of glutamate receptor. Neuron 13: 929-936

39. Lipton SA, Rayudu PV, Choi Y-B, Sucher NJ and Chen H-SV (1998) Redox modulation of the NMDA receptor by NO-related species. Prog. Brain Res. 118: 73-82

40. Lipton SA, Choi Y-B, Sucher NJ, Pan Z-H and Stamler JS (1996) Redox state, NMDA receptors, and NO-related species. Trends Pharmacol. Sci. 17: 186-187

41. Sucher NJ, Awobuluyi M, Choi Y-B and Lipton SA (1996) NMDA receptors: from genes to channels. Trends Pharmacol. Sci. 17: 348-355

42. Sucher NJ, Akabarian S, Chi CL, Leclerc CL, Awobuluyi M, Deitcher DL, Wu MK, Yuan JP, Jones EG and Lipton SA (1995) Developmental and regional expression pattern of a novel NMDA receptor-like subunit (NMDAR-L) in the rodent brain. J. Neurosci. 15:6509-6520.

43. Ciabarra AM, Sullivan JM, Gahn LG, Pecht G, Heinemann S and Sevarino KA (1995) Cloning and characterization of $\chi^{-1}$ : A developmentally regulated member of a novel class of the ionotropic glutamate receptor family. J. Neurosci. 15: $6498-6508$

44. Das S, Sasaki YF, Rothe T, Premkumar LS, Takasu M, Crandall JE, Dikkes $P$, Connor DA, Rayudu P, Cheung W, Chen H-SV, Lipton SA and Nakanishi N (1998) Increased NMDA current and spine density in mice lacking the NMDAR subunit, NR3A. Nature 377-381

45. Armstrong N, Sun Y, Chen G-Q and Gouaux E (1998) Structure of a glutamatereceptor ligand-binding core in complex with kainate. Nature 395: 913-917

46. Aizenman E, Brimecombe JC, Potthoff WK and Rosenberg PA (1998) Why is the role of nitric oxide in NMDA receptor function and dysfunction so controversial? Progr. Brain Res. 118: 53-71

47. Xu L, Eu JP, Meissner G and Stamler JS (1998) Activation of the cardiac calcium release channel (ryanodine receptor) by poly-S-nitrosylation. Science 279 : $234-237$

48. Omerovic A, Chen S-J, Leonard JP and Kelso SR (1995) Subunit-specific redox modulation of NMDA receptors expressed in Xenopus oocytes. J. Recep. Sign. Transduc. Res. 15: 811-827

49. Lipton SA and Wang YF (1996) in Pharmacology of Cerebral Ischemia. Krieglstein J, ed (Medpharm Scientific Publishers: Stuttgart) pp. 183-191

50. Sathi S, Edgecomb P, Warach S, Manchester K, Donaghey T, Stieg PE, Jensen FE and Lipton SA (1993) Chronic transdermal nitroglycerin (NTG) is neuroprotective in experimental rodent stroke models. Soc. Neurosci. Abstr. 19: 849

51. Tenneti L, D'Emilia DM, Troy CM and Lipton SA (1998) Role of caspases in Nmethyl-D-aspartate-induced apoptosis of cerebrocortical neurons. J. Neurochem. 71: $946-959$ 
52. Ankarcrona M, DypbuktJM, Bonfoco E, Zhivotovsky B, Orrenius S, Lipton SA and Nicotera P (1995) Glutamate-induced neuronal death: A succession of necrosis or apoptosis depending on mitochondrial function. Neuron 15: 961-973

53. Dimmeler S, Haendeler J, Nehls M and Zeiher AM (1997) Suppression of apoptosis by nitric oxide via inhibition of interleukin-1 $\beta$-converting enzyme (ICE)like and cysteine protease protein (CPP)-32-like proteases. J. Exp. Med. 185: 601-607

54. Ogura T, Tatemichi M and Esumi H (1997) Nitric oxide inhibits CPP32-like activity under redox regulation. Biochem. Biophys. Res. Commun. 236: 365-369

55. Bolotina VM, Najibi S, Palacino JJ, Pagaon PJ and Cohen RA (1994) Nitric oxide directly activates calcium-dependent potassium channels in vascular smooth muscle. Nature 368: 850-853

56. Hess DT, Patterson SI, Smith DS and Skene JHP (1993) Neuronal growth cone collapse and inhibition of protein fatty acylation by nitric oxide. Nature 366:562565
57. Moriyoshi K, Masu M, Ishii T, Shigemoto R, Mizuno N and Nakanishi S (1991) Molecular cloning and characterization of the rat NMDA receptor [see comments]. Nature 354: 31-37

58. Aizenman E, Lipton SA and Loring RH (1989) Selective modulation of NMDA responses by reduction and oxidation. Neuron 2: 1257-1263

59. BonnerFT and Stedman G (1996) In: Methods in Nitric Oxide Research. Feelisch M, Stamler JS (eds). Chichester, UK: Wiley) pp. 3-27

60. Wink DA and Feelisch M (1996) In: Methods in Nitric Oxide Research. Feelisch M, Stamler JS (eds). Chichester, UK: Wiley, pp. 403-412

61. Doyle MP, Surendra MN, Broene RD and Guy JK (1988) Oxidation and reduction of hemoproteins by trioxodinitrite(II). The role of nitrosyl hydride and nitrite. J. Am. Chem. Soc. 110: 593-599 